\title{
Vendor selection and order allocation using an integrated fuzzy mathematical programming model
}

\author{
Farzaneh Talebi and Davood Jafari*
}

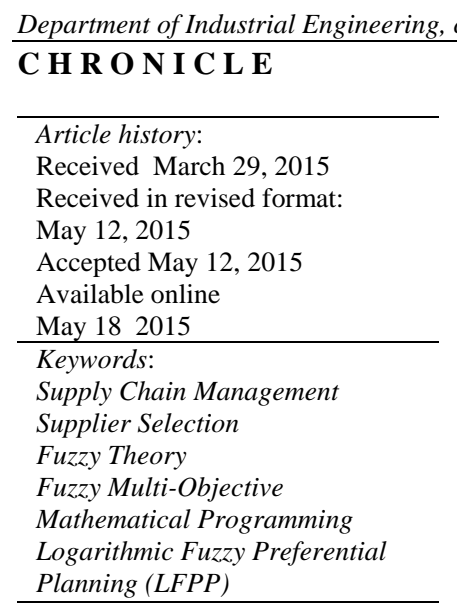
\begin{abstract}
A B S T R A C T
In the context of supply chain management, supplier selection plays a key role in reaching desirable production planning. In today's competitive world, many enterprises have focused on selecting the appropriate suppliers in an attempt to reduce purchasing costs and improve quality products and services. Supplier selection is a multi-criteria decision problem, which includes different qualitative and quantitative criteria such as purchase cost, on time delivery, quality of service, etc. In this study, a fuzzy multi-objective mathematical programming model is presented to select appropriate supplier and assign desirable order to different supplies. The proposed model was implemented for an organization by considering 16 different scenarios and the results are compared with two other existing methods.
\end{abstract}

(C) 2015 Growing Science Ltd. All rights reserved.

\section{Introduction}

In the context of supply chain management, supplier selection plays a key role in reaching desirable production planning (Chopra \& Meindl, 2007; Chai et al., 2013). In today's competitive world, many enterprises have focused on selecting the appropriate suppliers in an attempt to reduce purchasing costs and improve quality products and services (Dickson, 1966). Supplier selection is a multi-criteria decision problem, which includes different qualitative and quantitative criteria such as purchase cost, on time delivery, quality of service, etc. (Ghodsypour \& O’Brien, 2001). Ahi and Searcy (2013) presented a comparative literature analysis of definitions for green and sustainable supply chain management (Werners, 1988). They discussed the concept of green supply chain management (GSCM) and sustainable supply chain management (SSCM). They reported that definitions for GSCM were generally more narrowly concentrated than those for SSCM and put an emphasis on the characteristics

\footnotetext{
* Corresponding author

E-mail address: djafari5071@yahoo.com (D. Jafari) 
of environmental, flow, and coordination focuses. Amin et al. (2011) quantified SWOT (Strengths, Weaknesses, Opportunities and Threats) method in the context of supplier selection. SWOT is one of well-known methods for conducting strategic studies. Besides, they used the fuzzy logic and triangular fuzzy numbers with SWOT analysis to deal with vagueness of human thought. SWOT analysis may take into account both qualitative and quantitative criteria. The managers may understand the position of suppliers in a competitive environment using SWOT matrix. In addition, they used a fuzzy linear programming model to determine how much purchased should be accomplished from each supplier. Amin and Zhang (2012) proposed an integrated model in two phases where, they first proposed a framework for supplier selection criteria and then used a fuzzy method to evaluate suppliers based on qualitative criteria. They proposed a multi objective mixed-integer linear programming model to determine which suppliers and refurbishing sites should be selected, and reported the optimal number of parts and products in closed loop supply chain (CLSC) network. Arikan (2013) presented a multiple sourcing supplier selection problem as a multi objective linear programming problem. They proposed a fuzzy mathematical model and to satisfy the decision maker's aspirations for fuzzy goals. Awasthi et al. (2009) considered a supplier selection problem for a single manufacturer/retailer who encounters a random demand. All the available suppliers may provide various prices and may have restrictions on minimum and maximum order sizes. They determined a low-cost assortment of suppliers which is capable of satisfying the demand. Nazari-Shirkouhi et al. (2013) solved a supplier selection problem under multi-price level and multi-product using interactive two-phase fuzzy multi-objective linear programming (FMOLP) model. The model minimized total purchasing and ordering costs, a number of defective units, and late delivered units ordered from suppliers. Ozkok and Tiryaki (2011) proposed a compensatory fuzzy technique to solve multi-objective linear supplier selection problem with multiple-item (MLSSP-MI) by using Werners' “fuzzy and” ( $\left.\mu_{a n d}\right)$ operator. Shaw et al. (2012) proposed a method for supplier selection using fuzzy (Zadeh, 1965) analytical hierarchy process (AHP) and fuzzy multi-objective linear programming for developing low carbon supply chain. Yu et al. (2013) presented a mathematical model for optimal selection of retailers for a manufacturing vendor in a vendor managed inventory system.

\section{The proposed study}

In this paper, a fuzzy multi-objective mathematical programming model is presented to select supplier and assign order to different supplies. The proposed model is implemented for an organization by considering 16 different scenarios and the results are compared with two other existing methods.

\subsection{Notations}

$\begin{array}{ll}\text { Model index } & \text { Definitions } \\ i & \text { Spare parts } \\ j & \text { Supplier } \\ k & \text { Discount situation } \\ \text { Model parameters } & \text { definition } \\ p c_{i j k} & \text { Cost price of part } i \text { from supplier } j \text { in discount offered } k \\ d e f\left(r_{i j}\right) & \text { Value of deficit of part } i \text { from supplier } j \\ d e l\left(r_{i j}\right) & \text { Delivery time of part } i \text { from supplier } j \\ B & \text { Total budget cost } \\ S_{i j} & \text { Supplier capacity } j \text { for part } i \\ d e f \text { faccepted }\left(\mathrm{r}_{\mathrm{i}}\right) & \text { Total deficit of part } i \\ D_{i} & \text { Total demand for part } i \\ \mathrm{P}_{\mathrm{ij}} \text { min } & \text { Minimized value of part } i \text { received from supplier } j \\ \text { Decision variables } & \text { definition } \\ x_{i j k} & \text { Total value of part purchased item } i \text { from supplier } j \text { under discount condition } k \\ y_{j} & \text { Binary variable representing selection or not selection of supplier } i\end{array}$




\subsection{Assumption}

- Discount conditions are specified in contracts.

- No shortage is permitted.

- It is possible to order different parts from each supplier.

- One part can be purchased from different suppliers.

- Demand, budget and maximum acceptable failure rate are defined in fuzzy.

\subsection{Mathematical model}

The following presents the mathematical model

$$
\begin{aligned}
& \min \tilde{Z}_{1}=\sum_{i=1}^{n} \sum_{j=1}^{m} \sum_{k=1}^{l} p c_{i j k} x_{i j k} \\
& \min \tilde{Z}_{2}=\sum_{i=1}^{n} \sum_{j=1}^{m} \operatorname{def}\left(r_{i j}\right) x_{i j k} \\
& \min \tilde{Z}_{3}=\sum_{i=1}^{n} \sum_{j=1}^{m} \operatorname{del}\left(r_{i j}\right) x_{i j k}
\end{aligned}
$$

subject to

$\sum_{i=1}^{n} \sum_{j=1}^{m} \sum_{k=1}^{l} p c_{i j k} x_{i j k} \leq B$

$\sum_{i=1}^{n} \sum_{j=1}^{m} \sum_{k=1}^{l} x_{i j k} \leq S_{i j} y_{j}$

$\sum_{i=1}^{n} \sum_{j=1}^{m} \operatorname{def}\left(r_{i j}\right) x_{i j k} \leq d e f^{\text {accepted }}\left(r_{i}\right) x_{i j k}$

$\sum_{j=1}^{m} x_{i j k} \cong D_{i}, i=1, \cdots, n$

$x_{i j k} \tilde{\geq} P_{i j}^{\min } m j=1, \cdots, m$

$x_{i j k} \geq 0$ and integer, $i=2,3,4,5$

$Y_{j}=0,1$

The first objective function ( $\left.\mathrm{z}_{1}\right)$ minimizes total cost of purchased, the second objective function minimizes $\left(\mathrm{z}_{2}\right)$ the expected failure ratio and the last objective function $\left(\mathrm{z}_{3}\right)$ minimizes the delivery of all parts. The first constraint (Eq. (4)) is associated with the budget limitation, the second constraint (Eq. (5)) is related to capacity of suppliers while Eq. (6) specifies the maximum failure ratio. Eq. (7) determines demand for each part, Eq. (8) determines the minimum amount of purchased from each supplier and finally, Eq. (9) determines the type of variables.

\subsection{Fuzzy approach}

The proposed study of this paper uses fuzzy approach to handle uncertainty associated with different parameters. Let $w_{1}$ to $w_{3}$ be the weights associated with three objective functions, respectively. In addition, let $\omega_{1}$ to $\omega_{3}$ be the weights associated with budget, demand and failure constraints, respectively (Lai \& Hwang, 1993; Wang et al., 2009). The proposed study of this paper uses the following fuzzy model to handle uncertainty. 
$\max \gamma \lambda+(1-\gamma)\left(\sum_{\mathrm{j}=1}^{3} \mathrm{w}_{\mathrm{j}} \lambda_{\mathrm{j}}+\sum_{\mathrm{k}=1}^{3} \omega_{\mathrm{K}} \beta_{\mathrm{K}}\right)$

subject to

$\lambda_{\mathrm{j}} \leq \mu_{\mathrm{z}_{\mathrm{j}}}(\mathrm{x}), \quad \mathrm{j}=1,2,3$

$\beta_{\mathrm{K}} \leq \mu_{\mathrm{g}_{\mathrm{K}}}(\mathrm{x}), \quad \mathrm{k}=1,2,3$

$\mathrm{g}_{\mathrm{p}}(\mathrm{x}) \leq \mathrm{b}_{\mathrm{p}}, \quad \mathrm{p}=1,2, \ldots, \mathrm{M}$

$\lambda_{\mathrm{j}}, \beta_{\mathrm{K}} \in[0,1], \quad \mathrm{j}=1,2,3 \mathrm{k}=1,2,3$

$\lambda_{\mathrm{j}} \geq$ or $\leq \alpha$

$\sum_{\mathrm{j}=1}^{3} \mathrm{w}_{\mathrm{j}}+\sum_{\mathrm{k}=1}^{3} \omega_{\mathrm{K}}=1, \quad \mathrm{w}_{\mathrm{j}}, \omega_{\mathrm{K}} \geq 0$

$\mathrm{x}_{\mathrm{i}} \geq 0$

Moreover, the proposed study uses pair-wise comparison to find the relative importance of each weight based on the following mathematical model (Tiwari et al., 1987),

$\max \lambda$

subject to

$-w_{i}+l_{i j} w_{j}+\lambda\left(m_{i j}-l_{i j}\right) w_{j} \leq 0, i=1 \ldots, n-1 ; j=i+1, \ldots n$,

$w_{i}-u_{i j} w_{j}+\lambda\left(u_{i j}-m_{i j}\right) w_{j} \leq 0, i=1 \ldots, n-1 ; j=i+1, \ldots n$,

$\sum_{i=1}^{n} w_{i}=1$,

$w_{i} \geq 0 \quad i=1, \ldots, n$.

where

$\ln \tilde{a}_{i j} \approx\left(\ln l_{i j}, \ln m_{i j}, \ln u_{i j}\right), \quad i, j=1, \ldots ., n .$,

$\mu_{i j}\left(\ln \left(\frac{w_{i}}{w_{j}}\right)\right)=\left\{\begin{array}{ll}\frac{\ln \left(w_{i} / w_{j}\right)-\ln l_{i j}}{\ln m_{i j}-\ln l_{i j}}, & \ln \left(\frac{w_{i}}{w_{j}}\right) \leq \ln m_{i j} \\ \frac{\ln u_{i j}-\ln \left(w_{i} / w_{j}\right)}{\ln u_{i j}-\ln m_{i j}}, & \ln \left(\frac{w_{i}}{w_{j}}\right) \geq \ln m_{i j}\end{array}\right.$,

Therefore, we have

$\max 1-\lambda$

subject to

$$
\begin{aligned}
& \ln w_{i}-\ln w_{j}-\lambda \ln \left(\frac{m_{i j}}{l_{i j}}\right) \geq \ln l_{i j}, \quad i=1 \ldots, n-1 ; j=i+1, \ldots n \\
& -\ln w_{i}+\ln w_{j}-\lambda \ln \left(\frac{u_{i j}}{m_{i j}}\right) \geq-\ln u_{i j}, \quad i=1 \ldots, n-1 ; j=i+1, \ldots n \\
& w_{i} \geq 0, i=1, \ldots \ldots, n .
\end{aligned}
$$

Since $\lambda$ may receive different values including negative numbers we use the following fuzzy method, 
$\min J=(1-\lambda)^{2}+M \cdot \sum_{i=1}^{n-1} \sum_{j=i+1}^{n}\left(\delta_{i j}^{2}+\eta_{i j}^{2}\right)$

subject to

$$
\begin{aligned}
& x_{i}-x_{j}-\lambda \ln \left(\frac{m_{i j}}{l_{i j}}\right)+\delta_{i j} \geq \ln l_{i j}, \quad i=1 \ldots, n-1 ; j=i+1, \ldots n, \\
& -x_{i}+x_{j}-\lambda \ln \left(\frac{u_{i j}}{m_{i j}}\right)+\eta_{i j} \geq-\ln u_{i j}, \quad i=1 \ldots, n-1 ; j=i+1, \ldots n, \\
& \lambda, x_{i} \geq 0, \quad i=1, \ldots, n, \\
& \delta_{i j}, \eta_{i j} \geq 0, \quad i=1, \ldots, n-1 ; j=i+1, \ldots, n,
\end{aligned}
$$

Table 1 demonstrates the summary of fuzzy numbers and Table 2 shows the results of numbers assigned for various parameters.

\section{Table 1}

The summary of fuzzy numbers

\begin{tabular}{|c|c|c|c|c|c|c|c|c|c|c|c|c|c|c|c|c|c|c|}
\hline & \multicolumn{3}{|c|}{ Budget } & \multicolumn{3}{|c|}{ Demand } & \multicolumn{3}{|c|}{ Failure } & \multicolumn{3}{|c|}{ Cost $\left(\mathrm{Z}_{1}\right)$} & \multicolumn{3}{|c|}{ Failure $\left(\mathrm{Z}_{2}\right)$} & \multicolumn{3}{|c|}{ Delivery time $\left(\mathrm{Z}_{3}\right)$} \\
\hline & $\mathrm{L}$ & $\mathrm{m}$ & $\mathrm{u}$ & $\mathrm{L}$ & $\mathrm{m}$ & $\mathrm{u}$ & $\mathrm{L}$ & $\mathrm{m}$ & $\mathrm{u}$ & 1 & $\mathrm{~m}$ & $\mathrm{U}$ & $\mathrm{L}$ & $\mathrm{m}$ & $\mathrm{u}$ & $\mathrm{L}$ & $\mathrm{m}$ & $\mathrm{u}$ \\
\hline 1 & 1 & 1 & 1 & 1 & 1.3 & 1.7 & 0.8 & 0.8 & 1 & 2 & 3 & 4 & 1 & 5.3 & 6 & 4 & 5 & 6 \\
\hline 2 & 0.8 & 0.8 & 1 & 1 & 1 & 1 & 0.8 & 0.8 & 0.8 & 2 & 3 & 4 & 0.8 & 5 & 5.7 & 4 & 5 & 6 \\
\hline 3 & 1 & 1.3 & 1.7 & 1.3 & 1.7 & 2 & 1 & 1 & 1 & 2.3 & 3.3 & 4.3 & 1 & 5.7 & 6.3 & 4.3 & 5.3 & 6.3 \\
\hline 4 & 0.3 & 0.3 & 0.5 & 0.3 & 0.4 & 0.6 & 0.2 & 0.3 & 0.4 & 1 & 1 & 1 & 0.3 & 2.7 & 3.3 & 2.3 & 3.3 & 4.3 \\
\hline 5 & 0.2 & 0.2 & 0.3 & 0.2 & 0.3 & 0.4 & 0.2 & 0.2 & 0.3 & 0.5 & 0.6 & 0.8 & 0.1 & 1 & 1 & 0.8 & 1.5 & 2.3 \\
\hline 6 & 0.2 & 0.2 & 0.3 & 0.2 & 0.2 & 0.3 & 0.2 & 0.2 & 0.2 & 0.2 & 0.3 & 0.4 & 0.2 & 1 & 1.7 & 1 & 1 & 1 \\
\hline
\end{tabular}

\begin{tabular}{lccc}
\hline ES (Extremely Strong) & $(9,9,9)$ & RES & $(1 / 9,1 / 9,1 / 9)$ \\
IVS(Intermediate) & $(7,8,9)$ & RIVS & $(1 / 9,1 / 8,1 / 7)$ \\
VS(Very Strong) & $(6,7,8)$ & RVS & $(1 / 8,1 / 7,1 / 6)$ \\
IS(Intermediate) & $(5,6,7)$ & RIS & $(1 / 7,1 / 6,1 / 5)$ \\
S (Strong) & $(4,5,6)$ & RS & $(1 / 6,1 / 5,1 / 4)$ \\
IMS(Intermediate) & $(3,4,5)$ & RIMS & $(1 / 5,1 / 4,1 / 3)$ \\
MS (Moderately Strong) & $(2,3,4)$ & RMS & $(1 / 4,1 / 3,1 / 2)$ \\
IES (Intermediate) & $(1,2,3)$ & RIES & $(1 / 3,1 / 2,1)$ \\
E (Equally Strong) & $(1,1,1)$ & E & $(1,1,1)$ \\
\hline
\end{tabular}

\section{Table 2}

The summary of fuzzy numbers

\section{The results}

For the proposed study of this paper, we use 16 different scenarios and Table 3 presents the summary of the data used for this study.

\section{Table 3}

The summary of some input data

\begin{tabular}{lcccc}
\hline & & $\mu=0$ & $\mu=1$ & $\mu=0$ \\
\hline The total cost of the purchase & $\operatorname{min~} \mathrm{Z}_{1}$ & - & 33829 & 37349 \\
Failure rate & $\operatorname{min~} \mathrm{Z}_{2}$ & - & 11.94 & 12.23 \\
Delivery time & $\min \mathrm{Z}_{3}$ & - & 70835 & 77797 \\
Budget & $\mathrm{B}$ & 38000 & 48000 & 58000 \\
Product demand for part $i$ & $\mathrm{D}_{\mathrm{i}}$ & $\mathrm{D}$ i-0.05(D i) & $\mathrm{D} \mathrm{i}$ & $\mathrm{D}$ i+0.05(D i) \\
Accepted failure rate for part $i$ & def ac.(ri) & def ac.(ri)-0.05(def ac.(ri)) & def ac.(ri) & def ac.(ri)+0.05(def ac.(ri)) \\
\hline
\end{tabular}




\section{Table 4}

The summary of data for various scenarios calculated using FAHP

\begin{tabular}{cccccccc}
\hline \multirow{2}{*}{ Scenario } & $\gamma$ & $\mathrm{W}_{1}$ & $\mathrm{~W}_{2}$ & $\mathrm{~W}_{3}$ & $\omega_{1}$ & $\omega_{2}$ & $\omega_{3}$ \\
\cline { 3 - 8 } & & Cost & Failure & Delivery & Budget & Demand & Accepted failure \\
\hline S1 & 0.1 & 0.164534 & 0.147395 & 0.185511 & 0.138811 & 0.185511 & 0.178237 \\
S2 & 0.2 & 0.164534 & 0.147395 & 0.185511 & 0.138811 & 0.185511 & 0.178237 \\
S3 & 0.3 & 0.164534 & 0.147395 & 0.185511 & 0.138811 & 0.185511 & 0.178237 \\
S4 & 0.4 & 0.164534 & 0.147395 & 0.185511 & 0.138811 & 0.185511 & 0.178237 \\
S5 & 0.5 & 0.164534 & 0.147395 & 0.185511 & 0.138811 & 0.185511 & 0.178237 \\
S6 & 0.6 & 0.164534 & 0.147395 & 0.185511 & 0.138811 & 0.185511 & 0.178237 \\
S7 & 0.7 & 0.164534 & 0.147395 & 0.185511 & 0.138811 & 0.185511 & 0.178237 \\
S8 & 0.8 & 0.164534 & 0.147395 & 0.185511 & 0.138811 & 0.185511 & 0.178237 \\
S9 & 0.9 & 0.164534 & 0.147395 & 0.185511 & 0.138811 & 0.185511 & 0.178237 \\
S10 & 1 & 0.164534 & 0.147395 & 0.185511 & 0.138811 & 0.185511 & 0.178237 \\
S11 & 0 & 0.17 & 0.17 & 0.17 & 0.17 & 0.17 & 0.17 \\
S12 & 0 & 0.25 & 0.25 & 0.25 & 0.083 & 0.083 & 0.08 \\
S13 & 0 & 0.4 & 0.05 & 0.05 & 0.4 & 0.05 & 0.05 \\
S14 & 0 & 0.05 & 0.4 & 0.05 & 0.05 & 0.05 & 0.4 \\
S15 & 0 & 0.04 & 0.04 & 0.04 & 0.04 & 0.8 & 0.04 \\
S16 & 0 & 0.04 & 0.04 & 0.8 & 0.04 & 0.04 & 0.04 \\
\hline
\end{tabular}

We have solved the resulted problem under different scenarios and Fig. 1 shows the overall satisfaction under all possible scenarios.

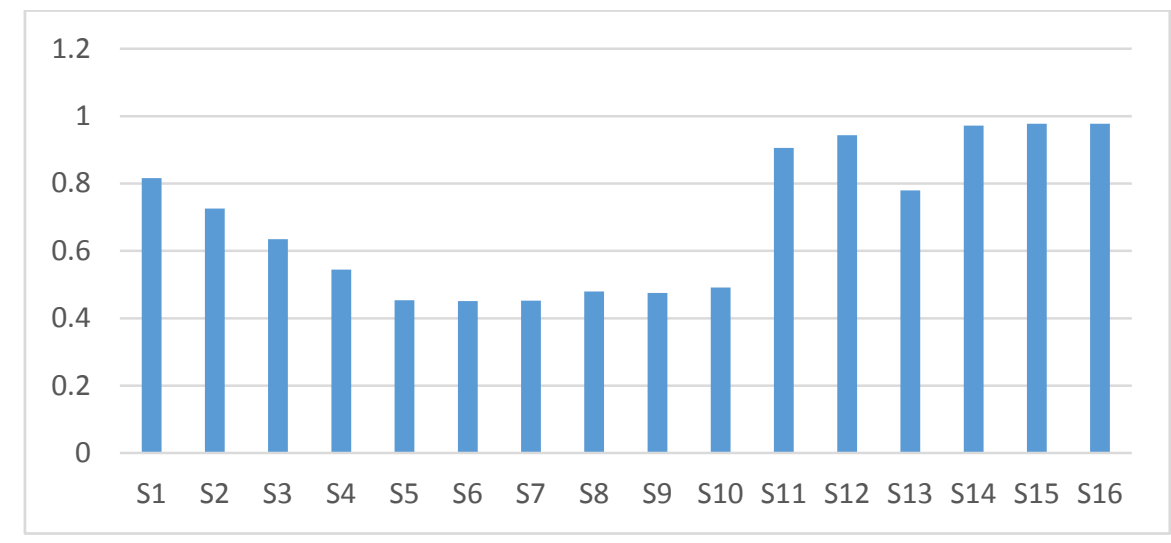

Fig. 1. The overall customer satisfaction under various scenarios

As we can observe from the results of Fig. 1, among different scenarios, six scenarios, 11, 12, 14, 15 and 16, appear to perform better than others although the purchase cost seems to be higher as shown in Fig. 2 as follows,

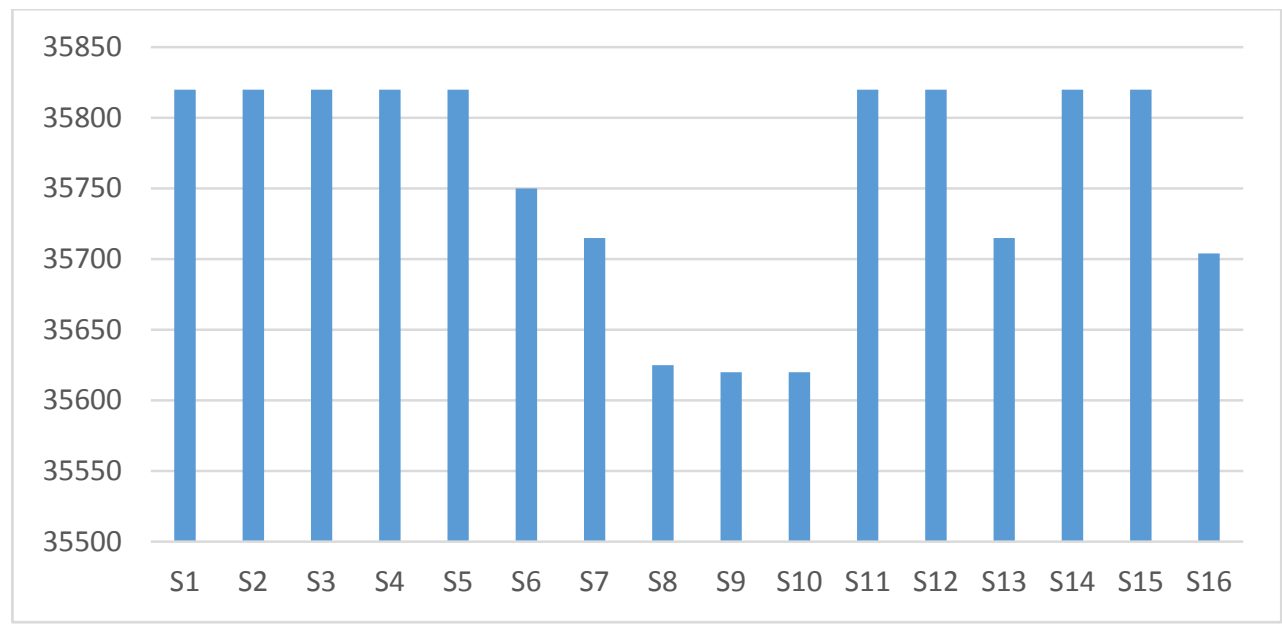

Fig. 2. The purchase cost 
This could be because of lower delivery time and failure, which are summarized in Fig. 3 and Fig. 4 as follows,

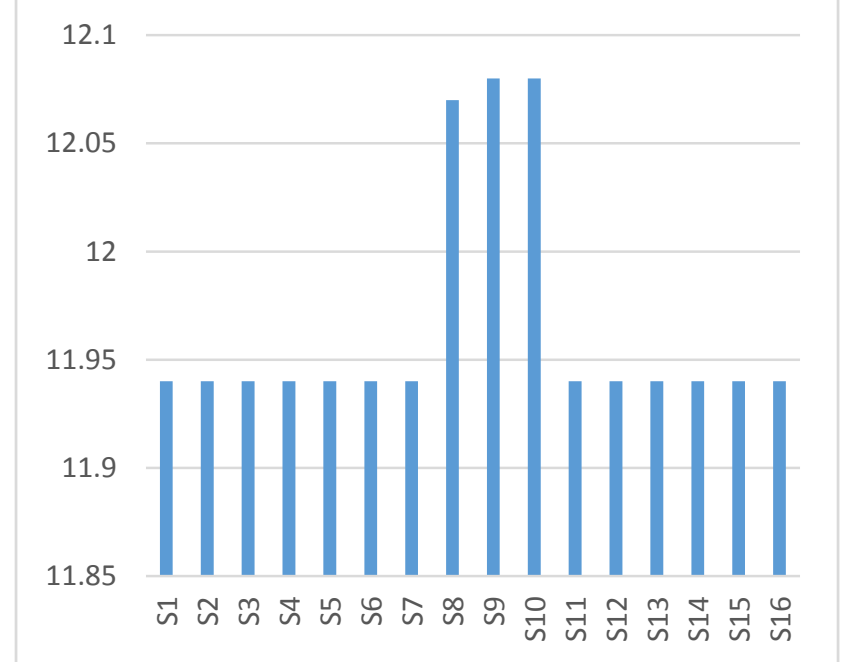

Fig. 3. The failure rate

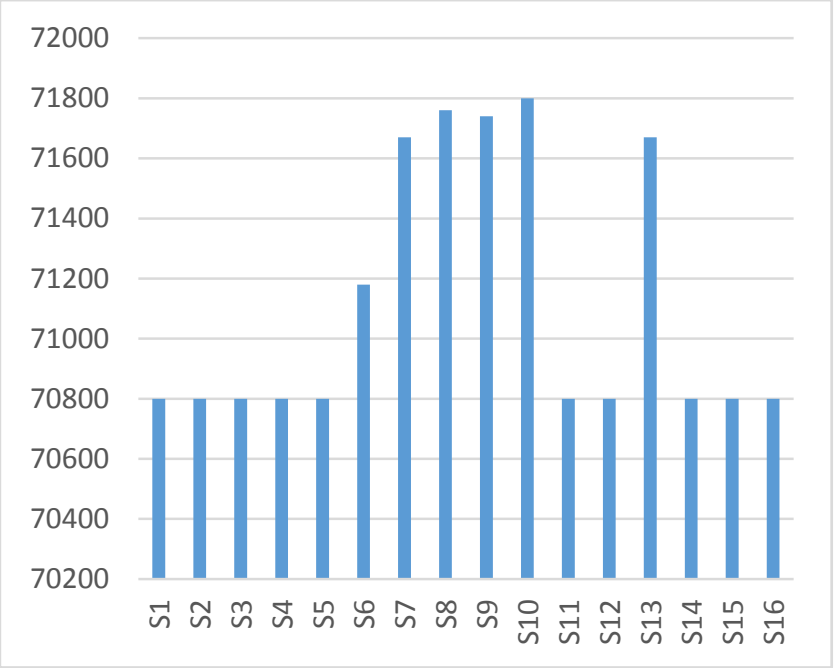

Fig. 4. The delivery time

\section{Conclusion}

In this paper, we have presented a fuzzy mathematical model for supplier selection and order allocation. The proposed study has considered three objective functions namely total purchase cost, delivery time and failure rate and using fuzzy analytical hierarchy process, the study has assigned weights for various objective functions as well as constraints. The study has implemented an efficient technique to convert the fuzzy mathematical problem into a crisp one and using 16 scenarios, the study analyzed the results. The preliminary results of this survey have conducted that the model could be practically used for realworld decision making issues.

\section{Acknowledgement}

The authors would like to thank the anonymous referees for constructive comments on earlier version of this paper.

\section{References}

Ahi, P., \& Searcy, C. (2013). A comparative literature analysis of definitions for green and sustainable supply chain management. Journal of Cleaner Production, 52, 329-352.

Amin, S. H., Razmi, J., \& Zhang, G. (2011). Supplier selection and order allocation based on fuzzy SWOT analysis and fuzzy linear programming. Expert Systems with Applications, 38(1), 334-342.

Amin, S. H., \& Zhang, G. (2012). An integrated model for closed-loop supply chain configuration and supplier selection: Multi-objective approach. Expert Systems with Applications, 39(8), 6782-6791.

Arikan, F. (2013). A fuzzy solution approach for multi objective supplier selection. Expert Systems with Applications, 40(3), 947-952.

Awasthi, A., Chauhan, S. S., Goyal, S. K., \& Proth, J.-M. (2009). Supplier selection problem for a single manufacturing unit under stochastic demand. International Journal of Production Economics, 117(1), 229-233.

Chai, J., Liu, J. N. K., \& Ngai, E. W. T. (2013). Application of decision-making techniques in supplier selection: A systematic review of literature. Expert Systems with Applications, 40(10), 3872-3885.

Chopra, S., \& Meindl, P. (2007). Supply Chain Management: Strategy, Planning, and Operation. (M. Pfaltzgraff, Ed.). New Jersey: Pearson Prentice Hall. 
Dickson, G. W. (1966). An analysis of vendor selection systems and decisions. Journal of Purchasing, 2(1), 5-17.

Ghodsypour, S. H., \& O’Brien, C. (2001). The total cost of logistics in supplier selection, under conditions of multiple sourcing, multiple criteria and capacity constraint. International Journal of Production Economics, 73(1), 15-27.

Lai, Y.-J., \& Hwang, C.-L. (1993). Possibilistic linear programming for managing interest rate risk. Fuzzy Sets and Systems, 54(2), 135-146.

Nazari-Shirkouhi, S., Shakouri, H., Javadi, B., \& Keramati, A. (2013). Supplier selection and order allocation problem using a two-phase fuzzy multi-objective linear programming. Applied Mathematical Modelling, 37(22), 9308-9323.

Ozkok, B. A., \& Tiryaki, F. (2011). A compensatory fuzzy approach to multi-objective linear supplier selection problem with multiple-item. Expert Systems with Applications, 38(9), 11363-11368.

Shaw, K., Shankar, R., Yadav, S., \& Thakur, L. S. (2012). Supplier selection using fuzzy AHP and fuzzy multi-objective linear programming for developing low carbon supply chain. Expert Systems with Applications, 8182-8192.

Tiwari, R. N., Dharmar, S., \& Rao, J. R. (1987). Fuzzy goal programming — An additive model. Fuzzy Sets and Systems, 24(1), 27-34.

Wang, J.-W., Cheng, C.-H., \& Huang, K.-C. (2009). Fuzzy hierarchical TOPSIS for supplier selection. Applied Soft Computing, 9(1), 377-386.

Werners, B. M. (1988). Aggregation models in mathematical programming. (G. Mitra, Ed.)Mathematical models for decision support. Berlin: Springer.

Yu, Y., Hong, Z., Zhang, L. L., Liang, L., \& Chu, C. (2013). Optimal selection of retailers for a manufacturing vendor in a vendor managed inventory system. European Journal of Operational Research, 225(2), 273-284.

Zadeh, L. (1965). Fuzzy sets. Information Control, 8, 338-353. 